\title{
Chronic inflammation exacerbates glucose metabolism disorders in C57BL/6 J mice fed with high-fat diet
}

\author{
Yu Wu', Tingting $\mathrm{Wu}^{1}$, Jun $\mathrm{Wu}^{1}$, Lei Zhao', Qing $\mathrm{Li}^{1}$, Zac Varghese ${ }^{2}$, John F Moorhead ${ }^{2}$, \\ Stephen H Powis ${ }^{2}$, Yaxi Chen' ${ }^{1}$ and Xiong Z Ruan ${ }^{1,2}$ \\ ${ }^{1}$ Key Laboratory of Metabolism of Lipid and Glucose, Centre for Lipid Research, The Second Affiliated Hospital of \\ Chongqing Medical University, Chongqing, China \\ ${ }^{2}$ John Moorhead Research Laboratory, Centre for Nephrology, University College London (UCL) Medical School, \\ Royal Free Campus, London, UK
}

\author{
Correspondence \\ should be addressed \\ to $Y$ Chen \\ Email \\ chenyaxi@cqmu.edu.cn
}

\begin{abstract}
Inflammatory stress is closely related to metabolic disease and insulin resistance. The precise cellular mechanism linking obesity and diabetes is largely unknown, but about $14-20 \%$ of obese individuals develop diabetes. In this study, we investigated whether chronic inflammation exacerbated glucose metabolism disorder by impairing $\beta$ cell function in high-fat diet (HFD)-fed C57BL/6J mice. We used s.c. casein injection to induce chronic inflammation in HFD-fed C57BL/6J mice; 14 weeks on a HFD resulted in weight gain, hyperlipidemia, and low insulin sensitivity in these mice which nevertheless had normal blood glucose and serum inflammatory cytokines levels. Casein injection in the background of HFD elevated serum tumor necrosis factor $\alpha(T N F \alpha)$ and serum amyloid A levels and increased TNF $\alpha$ and MCP1 expression in the adipose tissue, liver, and muscle of HFD-fed mice. Chronic inflammation induced by casein injection further decreased insulin sensitivity and insulin signaling, resulting in insulin deficiency and hyperglycemia in these mice. Islet mass and insulin content were markedly increased in HFD mice. However, in contrast with HFD-fed alone, chronic inflammation in HFD-fed mice decreased both islet mass and insulin content, reduced the genetic expression of insulin synthesis and secretion, and increased $\beta$ cell apoptosis. We conclude that chronic inflammation exacerbated glucose metabolism disorders by impairing $\beta$ cell function in HFD-fed C57BL/6J mice, suggesting that this mechanism may operate in obese individuals with chronic inflammation, making them prone to hyperglycemia.
\end{abstract}

\section{Key Words}

- glucose metabolism

- inflammatory diseases

- insulin

- apoptosis

- pancreas
Journal of Endocrinology (2013) 219, 195-204

\section{Introduction}

Obesity is an independent risk factor for type 2 diabetes (T2DM). However, it is estimated that currently $14-20 \%$ of Chinese with obesity suffer from diabetes, which leads the question of why all obese patients do not develop T2DM (Chen 2008). Decoding the relationship between obesity and diabetes requires complex interdisciplinary research on the cellular mechanisms that link the two conditions (Prentki \& Nolan 2006, Eckel et al. 2011).

T2DM is characterized by inadequate pancreatic $\beta$ cell compensation in the presence of chronic insulin resistance. Numerous studies have shown that insulin resistance is the central component of the metabolic 
syndrome and an important pathophysiological factor in the initiation and development of T2DM. However, a compensatory increase in insulin secretion makes most obese insulin-resistant individuals normoglycemic. Hyperglycemia is due to relative insulin deficiency, implying that T2DM develops in obese insulin-resistant subjects with the onset of $\beta$ cell dysfunction (Ferrannini \& Mari 2004, Defronzo 2009). Pancreatic $\beta$ cell function declines in chronic insulin resistance as people progress from normal to impaired glucose tolerance and then to diabetes. T2DM development begins when $\beta$ cell dysfunction first appears and before the onset of prediabetes, when glycemia is still within the normal range (Godsland et al. 2004). Much less is known about the causes and mechanisms of progressive deterioration in $\beta$ cell function leading to impaired glucose tolerance and diabetes (Xiang et al. 2010a).

Obesity, insulin resistance, and T2DM are closely associated with chronic inflammation characterized by abnormal cytokine production, increased acute-phase reactants and other mediators, and activation of a network of inflammatory signaling pathways (Hotamisligil 2006). The expansion of adipose tissue depots in obesity leads to elevated levels of adipocyte-derived circulating inflammatory cytokines, such as interleukin 6 (IL6), serum amyloid A (SAA), and tumor necrosis factor $\alpha$ (TNF $\alpha$ ). Many lines of evidence have shown that chronic activation of inflammatory pathways within insulin-target tissues can lead to obesity-related insulin resistance (Boden \& Shulman 2002, Schenk et al. 2008). Consistent with this, elevated levels of the inflammatory cytokines TNF $\alpha$, IL6, and C-reactive protein (CRP) have been shown in individuals with insulin resistance and diabetes (de Luca \& Olefsky 2008, Wang et al. 2008).

Given that T2DM is characterized by hyperglycemia, dyslipidemia, and increased circulating inflammatory factors (so-called low-grade inflammation), elevated inflammatory cytokines may play a role in the process of obesity-related $\beta$ cell destruction. S.c. casein injection is an established method for the induction of chronic systemic inflammation in mouse models. This has been used in many studies of atherosclerosis and liver steatosis (Miura et al. 1985, Wal 2002, Ma et al. 2008). In comparison with other sole cytokine or lipopolysaccharide (LPS)-induced mouse models, casein injection induces a lower degree inflammatory stress characterized by increased multiple cytokines (IL1 $\beta$, TNF $\alpha$, and IL6) and SAA (like CRP in human) levels in serum, which is more likely to mimic chronic systemic inflammatory state observed in patients with inflammatory stress (Zhang et al. 2008). The current study was undertaken to investigate whether chronic inflammation induced by casein injection exacerbated pancreatic $\beta$ cell dysfunction resulting in hyperglycemia in high-fat diet (HFD)-fed C57BL/6J mice and to explore its underlying mechanism.

\section{Materials and methods}

\section{Animal model}

Animal care and experimental procedures were performed with approval from the Animal Care Committee of Chongqing Medical University. Eight-week-old male C57BL/6J mice were fed with a normal chow diet (NCD) or a HFD or HFD plus s.c. injection of $0.5 \mathrm{ml} 10 \%$ casein (HFD + casein) for 14 weeks (HFD: TD88137, 60\% energy by fat; Harlan Laboratories Inc., Madison, WI, USA). Mice were injected on alternate days and were culled 14 weeks after the first injection. At termination, blood samples were taken for cytokines and lipid assays, and tissue samples were collected for further detection. For biochemical analysis of insulin signaling, another set of the mice in each group was fasted overnight and injected i.p. with insulin at a dose of $5 \mathrm{mU} / \mathrm{g}$ body weight (Sigma) for $10 \mathrm{~min}$ before adipose tissues, liver, and skeletal muscle were taken and snap-frozen in liquid nitrogen immediately after resection and stored at $-80^{\circ} \mathrm{C}$ (Zhang et al. 2012).

\section{Serum analysis}

Serum TNF $\alpha$ and SAA protein were measured by ELISA Kits (HuaMei Biotech, Wu Han, China). Serum triglycerides (TG) concentrations were determined enzymatically with commercial kits (Jiancheng, Nanjing, China). Serum free fatty acids (FFA) concentrations were determined calorimetrically using commercial kits (Applygen Technologies, Beijing, China). Insulin levels in the serum were detected by ELISA Kits (Millipore, Billerica MA, USA).

\section{Quantitative measurement of TG and FFA in adipose tissue}

Quantitative measurements of TG and FFA were performed using commercial kits (Jiancheng and HuaMei Biotech). Briefly, white adipose tissue (epididymal fat pads) were collected and lipids were extracted by the addition of $1 \mathrm{ml}$ solvents (TG, heptane/isopropanol= $2 / 3.5$ and FFA, chloroform/heptane/methanol $=5 / 5 / 1$ ). The lipid phase was collected and vacuum dried. The concentration of TG and FFA was analyzed using standards and normalized by total protein from tissues.

Published by Bioscientifica Ltd. 


\section{Glucose tolerance tests}

Before the glucose tolerance tests (GTT), mice were starved overnight but allowed free access to water. Glucose tolerance was tested by the i.p. injection of $2 \mathrm{mg}$ D-glucose/g body weight (Sigma). Blood glucose concentrations were determined in blood, which were taken from the cut tail tip, before and 15, 30, 60, and 120 min after the administration of glucose. The glucose concentrations were determined using an ACCU-CHEK Advantage blood glucose meter (Roche).

\section{Insulin tolerance tests}

Before the insulin tolerance tests (ITT), mice were starved for $4 \mathrm{~h}$ but allowed free access to water. Insulin tolerance was measured by i.p. injection of $1 \mathrm{mU}$ insulin/g body weight (Sigma). The glucose concentrations in blood were determined using an ACCU-CHEK Advantage blood glucose meter (Roche), which were taken from the cut tail tip, before and 15 , 30,60 , and $120 \mathrm{~min}$ after the administration of insulin.

\section{Histology and immunohistochemistry}

Pancreas from C57BL/6J mice were sequentially fixed, dehydrated, infiltrated, and cut into 5 - $\mu \mathrm{m}$ paraffin-embedded tissue sections. Sections were stained with hematoxylineosin. Sections were cut from embedded pancreatic slices and deparaffinized in dimethyl benzene. The immunohistochemistry procedures were set up according to the manufacturer's instructions (Zsbio, Beijing, China). Sections were blocked using 3\% hydrogen peroxide and 10\% serum, and then incubated with primary antibody (anti-insulin and antiCD68, Bioss (Beijing, China)). Avidin anti-rabbit antibody served as the secondary antibody followed by the addition of HRP anti-avidin antibody. The HRP activity was detected using a DAB solution (Zsbio). Finally, the reaction was stopped and sections were counterstained with hematoxylin. The microscopic images were taken by a Zeiss microscope and insulin-positive cells were considered as functional $\beta$ cells. Using WCIF ImageJ Software (NIH, Bethesda, MD, USA), the relative islet area to total pancreatic area ratio was calculated by random selection from magnifying fields at $10 \times$ objective. The islet mass was then evaluated by multiplying the area ratio with the pancreatic weight (Xiang et al. 2010b).

\section{$\beta$ cell apoptosis}

Free 3-hydroxy strand breaks resulting from DNA degradation were detected by the TUNEL technique according to the manufacturer's instructions (DeadEnd Fluorometric TUNEL System, Promega). To detect the $\beta$ cells, $5-\mu \mathrm{m}$ slices from paraffin-embedded tissue were incubated with rabbit anti-insulin antibody, followed by detection using the fluorescently labeled secondary antibody. The staining with DAPI was used for visualization of nuclei. The samples were immediately evaluated by fluorescence microscopy (Zeiss, Germany) for positively stained apoptotic nuclei. Positive cells costaining for insulin and TUNEL were designated as apoptotic $\beta$ cells. Results were expressed as the percentage of apoptotic $\beta$ cells, normalized by total insulin-positive cell number (Lacraz et al. 2010). To estimate $\beta$ cell apoptotic rates, counts (at $40 \times$ objective) from $500 \beta$ cells per pancreas section were analyzed under a Zeiss fluorescence microscope.

\section{Real-time RT-PCR}

Total RNA were isolated from pancreas homogenates from C57BL/6J mice using TRIzol reagent (Takara Life Technologies, Carlsbad, Japan). Real-time RT-PCR was performed in a Bio-Rad Sequence Detection System using SYBR Green dye (Applied Biosystems, Inc.) according to the manufacturer's protocol. All the primers (BGI, Beijing, China) were designed by Primer Express Software V2.0 (Applied Biosystems) (Table 1). To normalize expression data, $\beta$-actin was used as an internal control gene.

\section{Western blot}

Cytoplasmic and nuclear proteins were extracted from pancreas using a commercial kit. Sample proteins were separated by SDS-PAGE in a Bio-Rad Mini Protean apparatus and then transferred to a PVDF membrane.

Table 1 Mouse primers for real-time PCR

\begin{tabular}{|c|c|}
\hline Gene & Mouse primers \\
\hline Bax & $\begin{array}{l}\text { F: 5'-GGCCTTTTTTGCTACAGGGTTT-3' } \\
\text { R: 5'-GTGTCTCCCCAGCCATCCT-3' }\end{array}$ \\
\hline$B C / 2$ & $\begin{array}{l}\text { F: } 5^{\prime} \text {-CCTGTGGATGACTGAGTACCTGAA-3 } \\
\text { R: } 5^{\prime} \text {-CTACCCAGCCTCCGTTATCCT-3' }\end{array}$ \\
\hline$P d x 1$ & $\begin{array}{l}\text { F: } 5^{\prime}-\text { CGCGTCCAGCTCCCTTT-3' } \\
\text { R: 5'-CCACGCGTGAGCTTTGGT-3' }\end{array}$ \\
\hline Glut2 & $\begin{array}{l}\text { F: } 5^{\prime} \text {-TGGAAGGATCAAAGCAATGTTG-3' } \\
\text { R: } 5^{\prime} \text {-CATCAAGAGGGCTCCAGTCAA-3 } 3^{\prime}\end{array}$ \\
\hline Gk & $\begin{array}{l}\text { F: } 5^{\prime} \text {-GCTTTTTGAGACCCGTTTTGTG-3' } \\
\text { R: } 5^{\prime} \text {-GCCTTCGGTCCCCAGAGT-3' }\end{array}$ \\
\hline Insulin & $\begin{array}{l}\text { F: 5'-CCATCAGCAAGCAGGTCAT-3' } \\
\text { R: } 5^{\prime} \text {-GGGTGTGTAGAAGAAGCCA-3' }\end{array}$ \\
\hline$\beta$-actin & $\begin{array}{l}\text { F: 5'-CGATGCCCTGAGGCTCTTT-3' } \\
\text { R: } 5^{\prime} \text {-TGGATGCCACAGGATTCCAT-3' }\end{array}$ \\
\hline
\end{tabular}

Published by Bioscientifica Ltd 
A
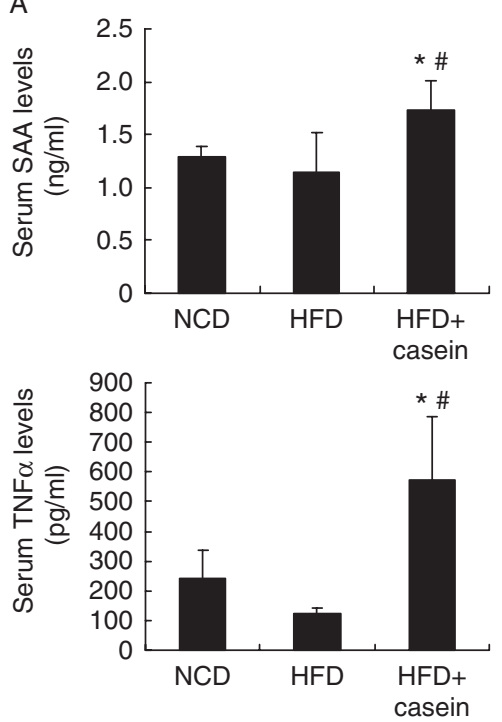
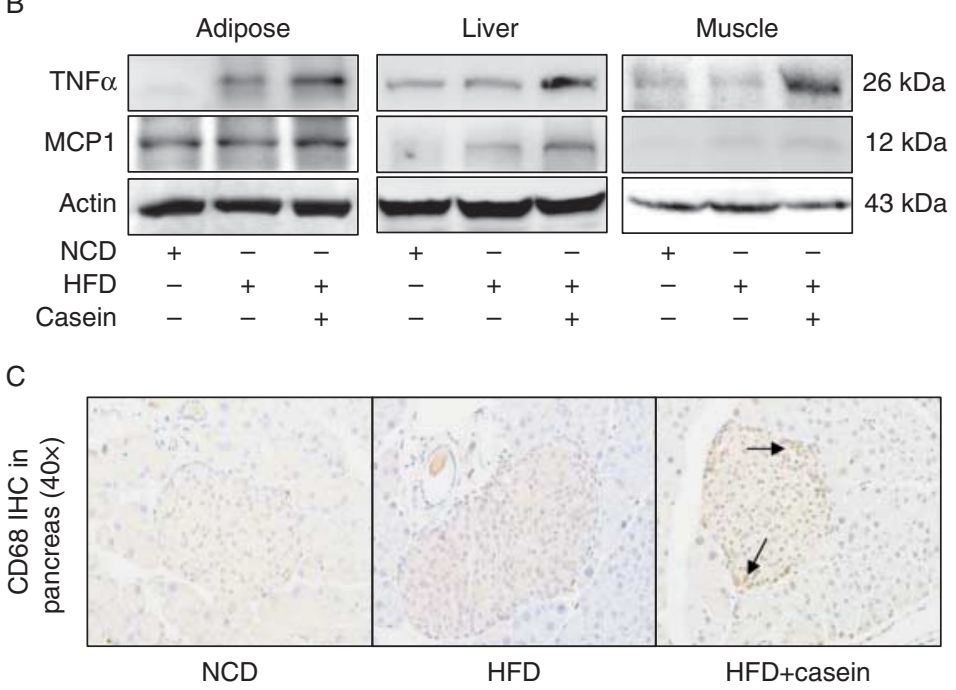

\section{Figure 1}

Casein injection induced chronic inflammation in C57BL/6J mice. Mice fed with normal chow diet (NCD), high-fat diet (HFD), and HFD plus casein injection (HFD + casein) were culled 14 weeks after first injection. (A) The levels of SAA and TNF $\alpha$ in the serum of C57BL/6J mice were examined by ELISA. Results represent the mean \pm s.D. $(n=6)$. ${ }^{\star} P<0.05$ vs NCD and

The membrane was blocked with $5 \%(\mathrm{w} / \mathrm{v})$ non-fat dried milk and incubated with primary antibodies (anti-TNF $\alpha$, anti-MCP1, anti-insulin receptor substrate 1 (IRS1), antiIRS2, anti-AKT, anti-p-AKT (ser473), anti-insulin, anti- $\beta$ actin, anti- $\beta$-tubulin, Santa Cruz Biotechnology, Inc.), followed by incubation with a secondary HRP-conjugated antibody. Finally, detection procedures were performed using ECL Advance Western Blotting Detection Kit (Amersham Bioscience). Band intensity volumes were measured by ImageJ Software.

\section{Statistical analysis}

Results are presented as means \pm s.D. In all experiments, data were evaluated for statistical significance using
${ }^{\#} P<0.05$ vs HFD. (B) The protein expression of TNF $\alpha$ and MCP1 in the adipose tissue, liver and muscle was detected by western blot. (C) Infiltration of inflammation cells in pancreas was detected by macrophage marker CD68 immunohistochemistry (original magnification $\times 40$ ), arrows show macrophages dyed brown.

one-way ANOVA followed by Q-test. A difference was considered significant if the $P$ value was $<0.05$.

\section{Results}

\section{Casein injection induced chronic inflammation in HFD-fed C57BL/6J mice}

A chronic low-grade systemic inflammation was induced in C57BL/6J mice using a combination of a HFD and s.c. injection of $10 \%$ casein on alternate days for 14 weeks. There were significant increases of SAA and TNF $\alpha$ concentration in the serum of casein-injected mice compared with mice fed with HFD (Fig. 1A), suggesting that chronic inflammation was successfully induced in

Table 2 Effects of HFD and casein injection on metabolic parameters in C57BL/6J mice. TG and FFA levels in the serum and adipose tissue of C57BL/6J mice were measured as described in Materials and methods section and results represent the mean \pm s.D. $(n=6)$

\begin{tabular}{lcc}
\hline & NCD \\
\cline { 1 - 2 } Body weight $(\mathrm{g})$ & & $22.75 \pm 1.27$ \\
Adipose/body weight $(\mathrm{g} / \mathrm{g})$ & & $0.014 \pm 0.002$ \\
Serum TG levels $(\mathrm{mmol} / \mathrm{l})$ & & $3.84 \pm 0.91$ \\
Serum FFA levels $(\mu \mathrm{g} / \mathrm{ml})$ & & $1.52 \pm 0.23$ \\
Adipose TG levels $(\mathrm{mg} / \mathrm{mg})$ & & $0.83 \pm 0.27$ \\
Adipose FFA levels $(\mathrm{ng} / \mathrm{mg})$ & & $1.26 \pm 0.53$ \\
\hline
\end{tabular}

\begin{tabular}{c}
\hline HFD \\
\hline $27.03 \pm 1.31 *$ \\
$0.036 \pm 0.01 *$ \\
$5.67 \pm 0.84^{\star}$ \\
$2.31 \pm 0.55^{*}$ \\
$2.42 \pm 0.22^{*}$ \\
$12.60 \pm 4.79 *$ \\
\hline
\end{tabular}

\begin{tabular}{c}
\hline HFD + casein \\
\hline $25.73 \pm 1.38^{*}$ \\
$0.035 \pm 0.004^{*}$ \\
$4.41 \pm 1.02$ \\
$2.59 \pm 0.10^{*}$ \\
$2.19 \pm 0.24^{*}$ \\
$11.79 \pm 0.96^{*}$ \\
\hline
\end{tabular}

$\star P<0.05$ vs NCD 
C57BL/6J mice. We also detected the inflammatory cytokine productions in mouse adipose tissue, liver, and muscle. The protein expression of TNF $\alpha$ and MCP1 in the three types of tissues in HFD group slightly increased compared with NCD group (Fig. 1B), while inflammatory cytokines in the serum were kept in the normal levels (Fig. 1A). Casein-injected mice had a higher expression of TNF $\alpha$ and MCP1 protein compared with the other two groups (Fig. 1B), indicating that casein injection aggravated local inflammation in HFD-fed mice. Immunohistochemical analyses of pancreatic sections revealed that CD68, a specific marker of tissue macrophages, was increased in casein injection group (Fig. 1C). It indicated that casein injection also induced pancreatic inflammation in $\mathrm{C} 57 \mathrm{BL} / 6 \mathrm{~J}$ mice.

\section{Effects of HFD and chronic inflammation on metabolic parameters in C57BL/6J mice}

HFD feeding for 14 weeks obviously increased body weight, adipose/body weight, serum and adipose TG, and FFA levels, and induced dyslipidemia in C57BL/6J mice. Compared with the mice fed with HFD, casein injection had no further effect on these parameters mentioned above (Table 2).

\section{Chronic inflammation aggravated insulin resistance and glucose metabolism disorders in HFD-fed C57BL/6J mice}

The fasting glucose levels were unchanged in HFD-fed mice compared with NCD-fed mice (Fig. 2A and C). After glucose challenge, blood glucose concentration of HFD group was persistently higher than that of the NCD group (Fig. 2A), suggesting that HFD feeding for 14 weeks induced glucose intolerance in mice. Insulin levels in serum were significantly increased in HFD-fed mice (Fig. 2D). After insulin loading, blood glucose levels decreased slowly and still higher in the HFD group (Fig. 2B), suggesting that HFD feeding reduced insulin sensitivity in mice. We also measured the major molecules involved in insulin signaling in insulin-sensitive tissues. HFD inhibited the levels of total IRS1, IRS2, and p-AKT:AKT ratio in the liver, muscle, and adipose tissue (Fig. 3), indicating that HFD impaired insulin signaling and induced insulin resistance in mice.

Casein injection further aggravated impaired glucose tolerance, showing higher blood glucose levels after glucose injection and lower ITT slope after insulin loading in the casein plus HFD group (Fig. 2A and B). Caseininjected mice had a notable increase in fasting glucose levels (Fig. 2A and C) and decrease insulin levels in serum
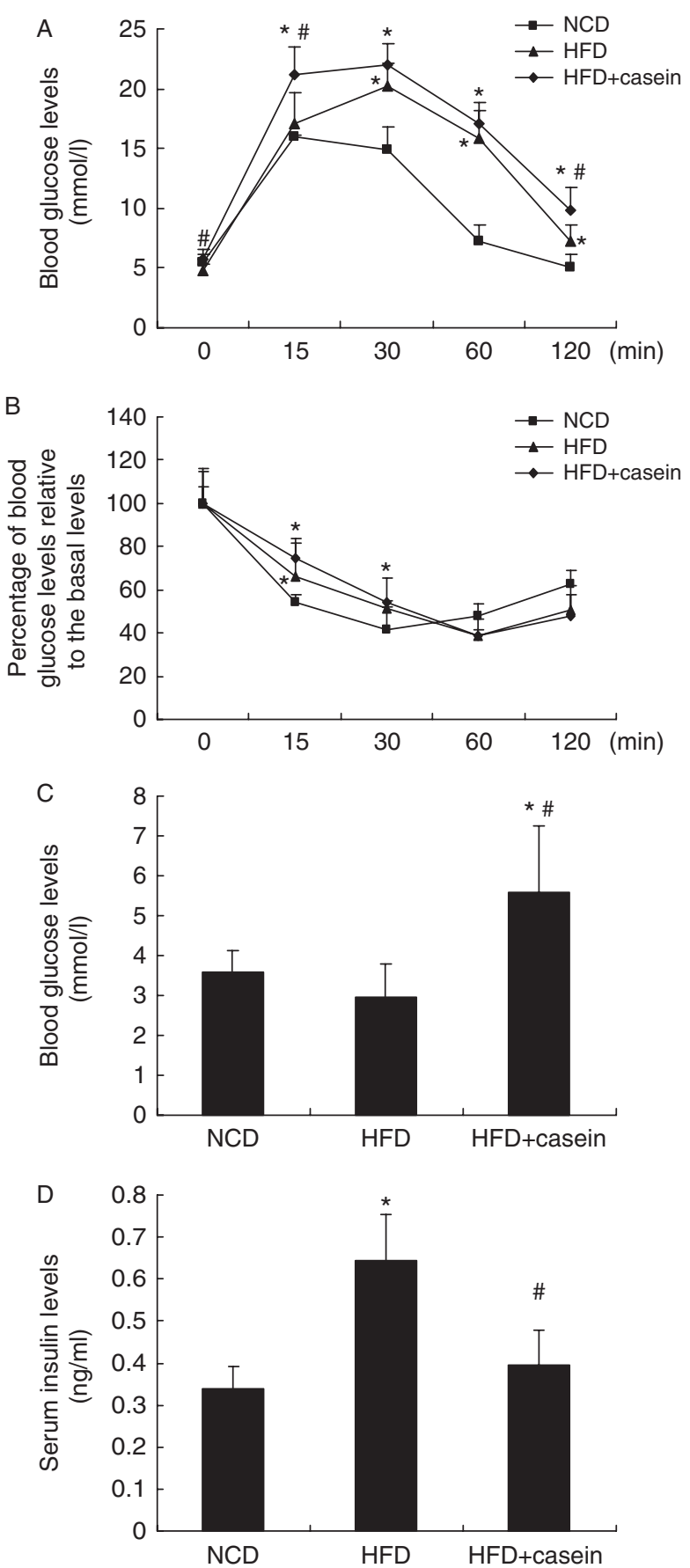

Figure 2

Chronic inflammation further impaired glucose tolerance and decreased insulin sensitivity in HFD-fed C57BL/6J mice. (A) Glucose tolerance tests (glucose-stimulated blood glucose concentrations, GTT) performed after 14 weeks of treatment in C57BL/6J mice starved overnight. (B) Insulin tolerance tests (insulin-stimulated blood glucose concentrations, ITT) performed at the end of experiments in C57BL/6J mice starved for $4 \mathrm{~h}$. Mice were starved overnight before executed and the blood was collected for fasting blood glucose (C) and serum insulin (D) detection. Results represent the mean \pm s.D. $(n=6) .{ }^{*} P<0.05$ vs NCD and ${ }^{\#} P<0.05$ vs HFD.

Published by Bioscientifica Ltd. 


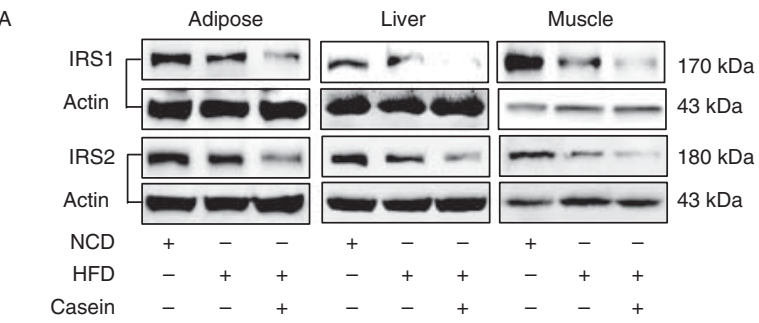

B
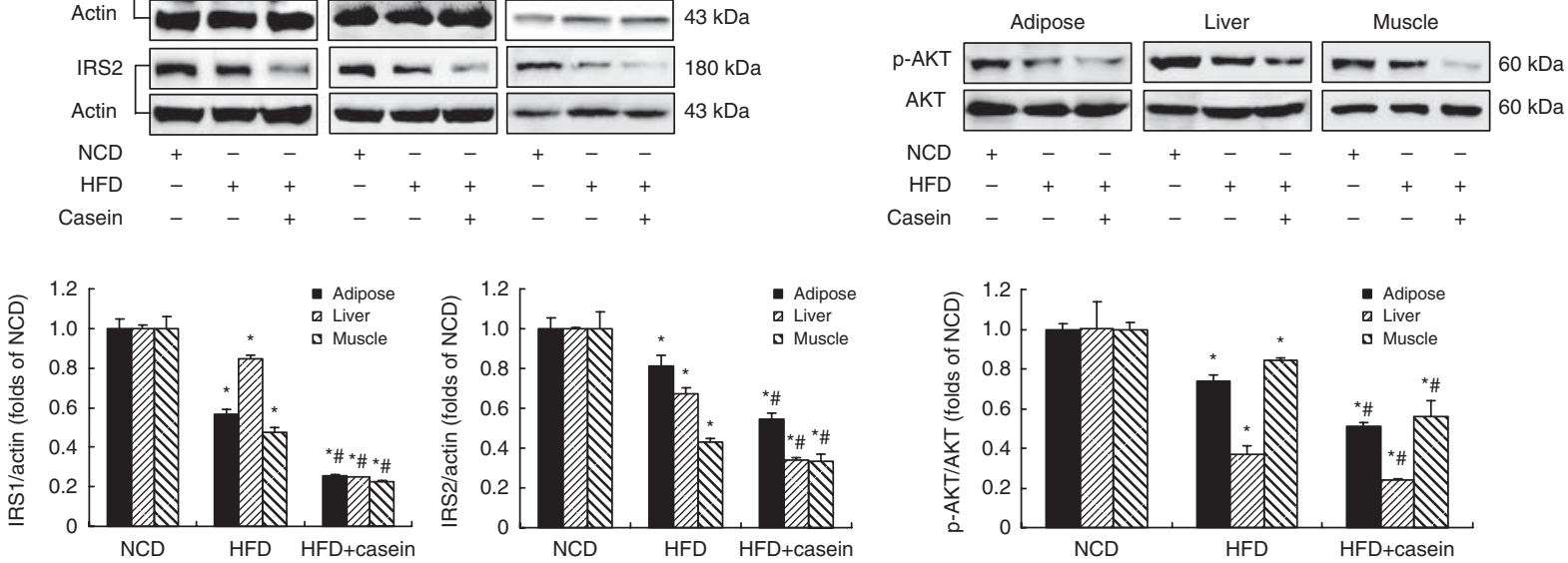

Figure 3

Chronic inflammation aggravated the impairment on insulin signaling in insulin-targeted tissues of HFD-fed mice. The protein expression of IRS 1 and IRS2 (A), p-AKT (ser473), and AKT (B) in the adipose tissue, liver, and muscle was detected by western blot. To analyze the p-AKT level, C57BL/6J mice were fasted overnight and injected i.p. with insulin for $10 \mathrm{~min}$ before adipose tissues, liver, and skeletal muscle were excised. The histogram represents mean \pm s.D. $(n=3)$ of the densitometric scans for protein bands from three experiments, normalized by comparison with $\beta$-actin in adipose and liver and tubulin in muscle, and expressed as a percentage of NCD. ${ }^{*} P<0.05$ vs NCD and ${ }^{\#} P<0.05$ vs HFD.
(Fig. 2D), implying that chronic inflammation impaired $\beta$ cell function and induced hyperglycemia. Likewise, casein injection further downregulated IRS1, IRS2, and p-AKT protein expression (Fig. 3), and aggravated impaired insulin signaling induced by HFD.

\section{Chronic inflammation exacerbated pancreatic $\beta$ cell dysfunction in HFD-fed mice}

Results from pancreatic histomorphology (Fig. 4A, B and C) and quantitative analysis of insulin in pancreas (Fig. 4D) showed that islet mass and insulin content were markedly increased in HFD-fed mice compared with NCD-fed mice. However, casein injection impaired $\beta$ cell function by reducing islet mass and insulin content in HFD-fed mice (Fig. 4A, B, C and D). We further determined the expression of key participants in $\beta$ cell functional integrity, namely pancreatic duodenal homeobox 1 (PDX1), glucokinase (GK), glucose transporter 2 (GLUT2), and insulin. The mRNA expression of $P d x 1$ and $G k$ had no obvious change, while both Glut2 (Slc2a2) as well as insulin mRNA levels were significantly increased in HFD group (Fig. 4E), indicating that a HFD for 14 weeks had no effect on insulin biosynthesis but enhanced insulin secretion. The mRNA expression of $P d x 1$, Glut2, $G k$, and insulin were significantly downregulated in casein-injected mice (Fig. 4E), indicating that chronic inflammation reduced insulin biosynthesis and secretion in HFD-fed mice.

\section{Chronic inflammation increased $\beta$ cell apoptosis in HFD-fed mice}

Data showed that apoptotic $\beta$ cell numbers had no difference between HFD group and NCD group (Fig. 5A and $\mathrm{B})$. However, casein injection notably increased $\beta$ cell apoptosis (Fig. 5A and B) and upregulated pancreatic Bax/Bcl2 mRNA expression in mice fed with HFD (Fig. 5C), suggesting that chronic inflammation exacerbated $\beta$ cell apoptosis in HFD-fed mice.

\section{Discussion}

Chronic systemic inflammation plays an important role in the pathogenesis of multiple metabolic disorders, including insulin resistance, T2DM, and obesity. Most obese individuals do not develop diabetes because $\beta$ cells initially compensate for insulin resistance. Clinical studies have identified elevated serum levels of TNF $\alpha$ and IL6 as risk factors for subjects developing into T2DM (Spranger et al. 2003). We presume the progression of obesity-related $\beta$ cell dysfunction may be related to a state of chronic inflammation.

Published by Bioscientifica Ltd 
A

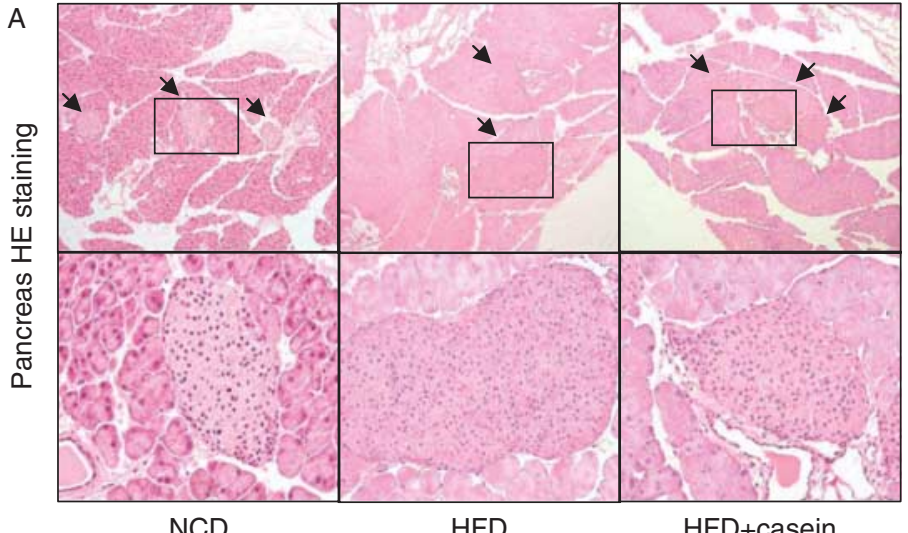

NCD

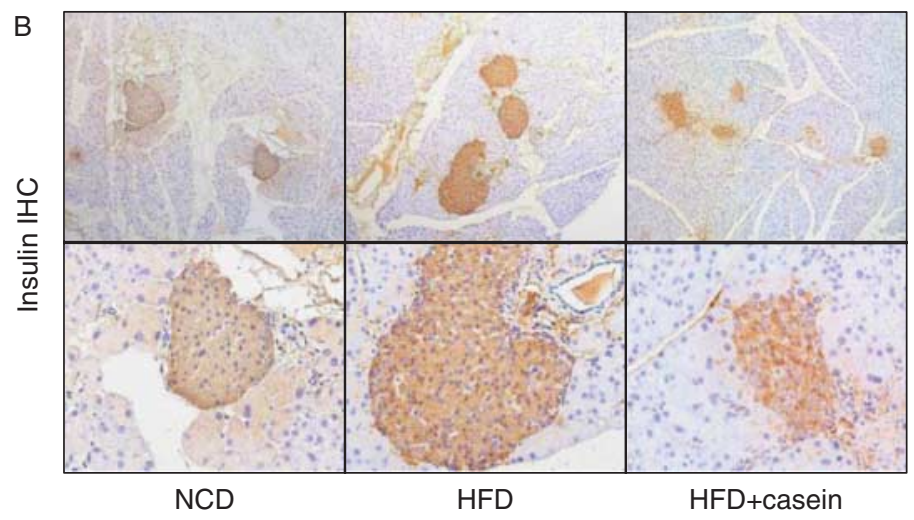

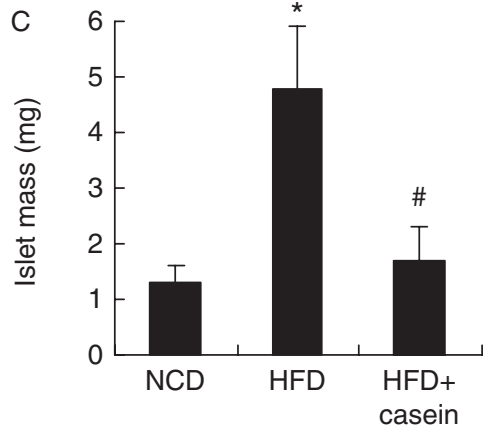

D
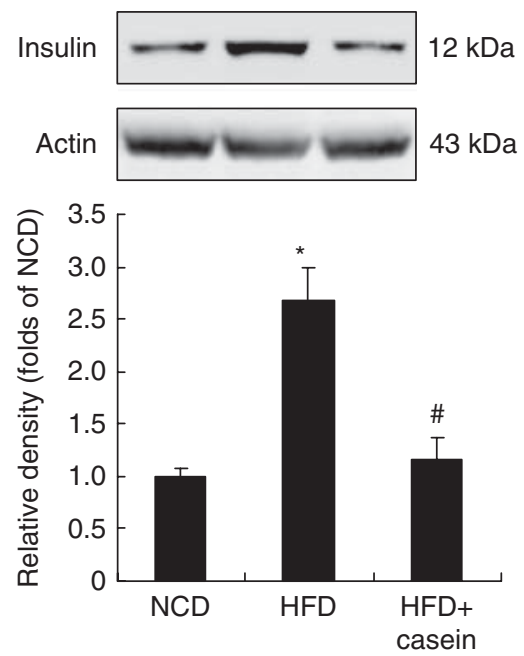

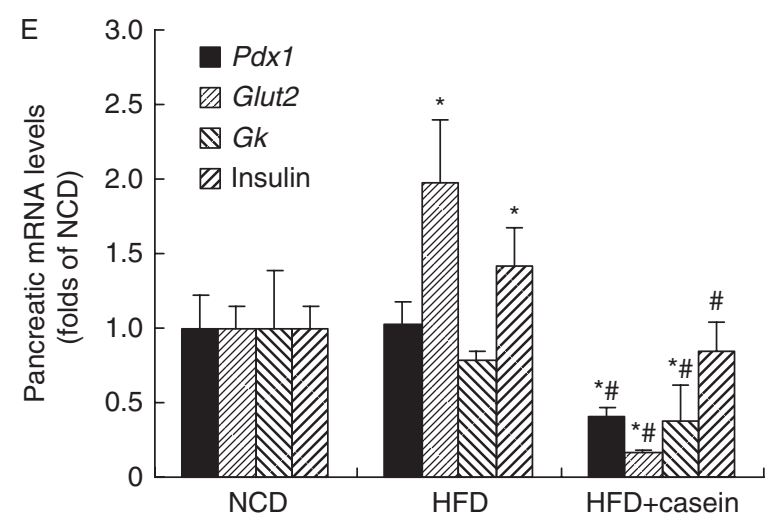

Figure 4

Chronic inflammation exacerbated pancreatic $\beta$ cell dysfunction in HFD-fed mice. (A) Hematoxylin-eosin (HE) staining in pancreas including the islet mass (boxed, arrows). (B) Insulin immunohistochemistry. Magnification $\times 10$ (top panels) and $\times 40$ (bottom panels). (C) Islet mass of C57BL/6J mice was calculated as described in Materials and methods section. Values are mean \pm s.D. $(n=6)$ in each group. (D) The protein levels of insulin in

A HFD in which fat contributes $58 \%$ of daily energy intake fat in a C57BL/6J mice model is a robust model for the study of insulin resistance, impaired glucose tolerance, and T2DM (Winzell \& Ahren 2004). Mice on long-term pancreas of C57BL/6J mice were detected by western blot. The histogram represents mean \pm s.D. $(n=3)$ of the densitometric scans for protein bands from three experiments, normalized by comparison with $\beta$-actin. (E) The mRNA expression of $P d x 1, G l u t 2, G k$, and insulin in pancreatic islet of C57BL/6J mice was detected by real-time PCR. Results represent the mean \pm s.D. $(n=6)$. ${ }^{\star} P<0.05$ vs NCD and ${ }^{\#} P<0.05$ vs HFD.

HFD revealed $\beta$ cell dysfunction and diminution of glucose-induced insulin secretion and developed glucose intolerance as a result of insulin resistance (Collins et al. 2010). In this study, C57BL/6J mice on a HFD for 14 weeks

Published by Bioscientifica Ltd. 
A
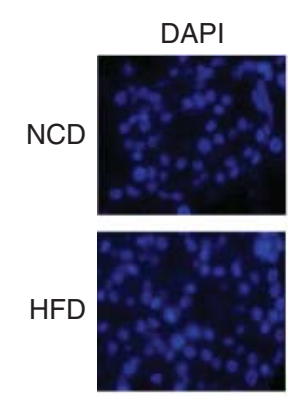

HFD+
casein
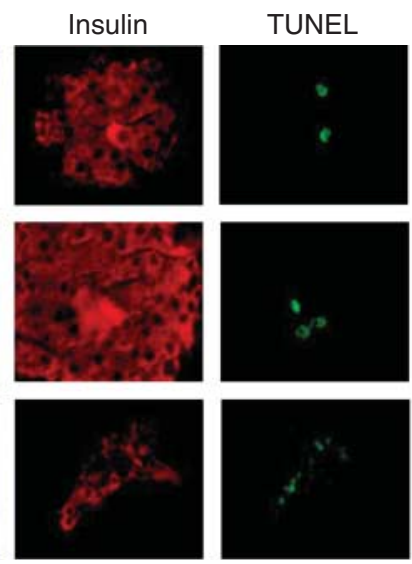
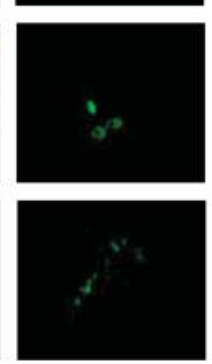

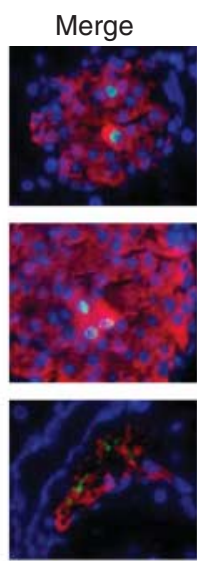

B

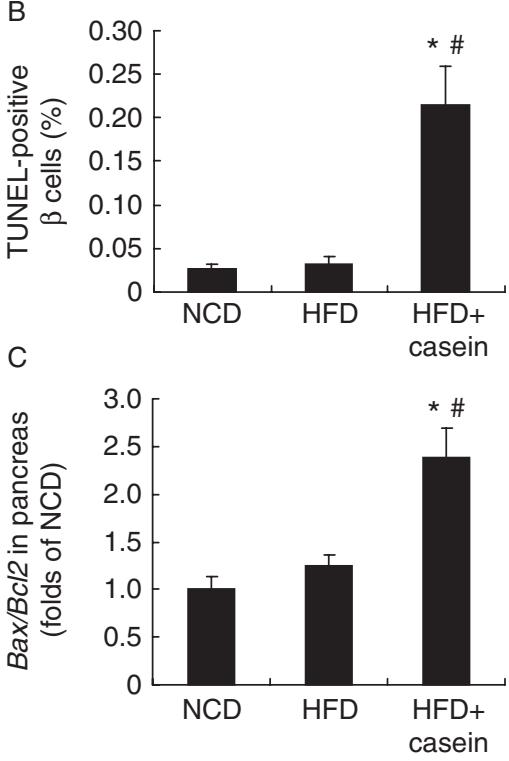

\section{Figure 5}

Chronic inflammation aggravated $\beta$ cell apoptosis in HFD-fed mice.

(A) Apoptosis of insulin-expressing cells on islet sections was determined by the TUNEL assay. Representative examples of pancreatic islets stained by immunofluorescence for insulin (red), marker of cell apoptosis TUNEL (green), and nuclear stain DAPI (blue) imaged at $100 \times$. (B) The

revealed characteristic of obesity and hyperlipidemia. HFD-fed mice revealed glucose intolerance and decreased insulin sensitivity, accompanied by impaired insulin signaling suggesting that a 14 -week HFD induced insulin resistance in C57BL/6J mice. In our experimental setting, there were no change in serum SAA and TNF $\alpha$ levels but increase in $\mathrm{TNF} \alpha$ and MCP1 expression in the adipose tissue, liver, and muscle in HFD-fed mice compared with NCD-fed mice, in agreement with previous reports on overexpression of TNF $\alpha$ in different white adipose tissue depots of obese individuals and a normal circulating serum TNF $\alpha$ level (Hotamisligil et al. 1995).

The bacterial endotoxin, LPS, induced inflammatory stress is presented during endotoxic septic shock, a condition that often leads to multiple organ failure and mortality (Zhang et al. 2008). LPS injection results in robust CNS-controlled sickness behaviors accompanied by increases in inflammatory cytokines (IL1 $\beta$, TNF $\alpha$, and IL6) in the blood and brain. Compared with the administration of LPS, the inflammation induced by casein is characterized by an increased SAA, which is well documented as a good marker of chronic low-grade systemic inflammation.

S.c. injection of casein in NCD alone-fed C57BL/6J mice had no obvious effect on metabolic parameters, such as body weight, serum FFA, and insulin levels (data not percentage of apoptotic $\beta$ cells was calculated as described in Materials and methods section. Values are mean \pm s.D. $(n=6)$ in each group. (C) Pancreatic Bax and Bc/2 mRNA expression of C57BL/6J mice was detected by real-time PCR. Results represent the mean \pm s.D. $(n=6)$. ${ }^{*} P<0.05$ vs NCD and ${ }^{\#} P<0.05$ vs HFD.

shown). In this study, we used casein injection in HFD-fed $\mathrm{C} 57 \mathrm{BL} / 6 \mathrm{~J}$ mice to investigate the role of inflammation in obesity-related $\beta$ cell dysfunction. Serum TNF $\alpha$ and SAA levels were significantly increased after casein injection for 14 weeks. Moreover, TNF $\alpha$ and MCP1 expressions in the adipose, liver, and muscle were upregulated in casein plus HFD group compared with HFD group, suggesting that casein injection successfully induced chronic systemic and local inflammation in HFD-fed mice.

In the obesity-induced metabolic disorder, FFA, which is commonly elevated in obese individuals, may drive a compensatory increase in $\beta$ cell mass and function followed by attenuation as T2DM develops (El Assaad et al. 2003, Maedler et al. 2003). Investigation of the effects of HFD and chronic inflammation on metabolic parameters in C57BL/6J mice revealed that HFD feeding for 14 weeks markedly increased serum TG and FFA levels in C57BL/6J mice, while casein injection did not increase serum TG and FFA contents in HFD-fed mice. We also investigated the effects of HFD and chronic inflammation on blood glucose and serum insulin in C57BL/6J mice. The data showed that HFD mice maintained normoglycemia in the presence of impaired GTT and higher serum insulin levels, whereas mice in the HFD plus casein injection group had notable hyperglycemia and low serum insulin

Published by Bioscientifica Ltd 
levels, implying that chronic inflammation accelerated deterioration of $\beta$ cell function. Compared with HFD-fed mice, casein-injected mice revealed parallel serum FFA levels and marked $\beta$ cell dysfunction, suggesting that chronic inflammation is an independent risk factor in the destruction of pancreatic $\beta$ cells.

The dysregulation of IRS1 and IRS2 and the inhibition of its signaling downstream are the primary mechanisms of chronic inflammation-induced insulin resistance. In this study, casein injection notably diminished the IRS1, IRS2, and p-AKT levels in the liver, muscle and adipose tissues of mice, and revealed obvious insulin resistance. Research showed that IRS1 was the principal mediator of hepatic insulin action that maintains glucose homeostasis, especially during nutrient excess. IRS1-deficient liver showed poor regulations of the key gluconeogenic genes and impaired glucose tolerance and insulin sensitivity. Moreover, IRS1 was required to suppress hepatic glucose production during hyperinsulinemic-euglycemic clamp (Guo et al. 2009). In this study, inflammatory stress induced by casein may affect hepatic glucose production and gluconeogenesis by inhibiting hepatic IRS1.

Data on the augmentation of islet mass and pancreatic insulin content in HFD-fed mice compared with NCD-fed mice showed that islet mass and pancreatic insulin content were markedly increased in HFD-fed mice, consistent with previous studies (Collins et al. 2010, Li et al. 2011). Islet adaptation to obesity is well established in rodents, where islets compensate for insulin-resistant states by increasing $\beta$ cell mass and function to maintain normoglycemia (Sachdeva \& Stoffers 2009). In this study, we found that chronic inflammation impaired $\beta$ cell function by reducing islet mass and pancreatic insulin content in HFD-fed mice. To explore the underlying mechanism of inflammation-mediated impairment in pancreatic islets of HFD-fed mice, we determined the expression of key participants in insulin synthesis and secretion. $P d x 1$ acts in $\beta$ cells as a house-keeping transcription factor for insulin gene expression (Melloul 2004). Gk, Glut2, and insulin are the three key components of the glucose-sensing machinery responsible for glucoseinducible insulin release (Tiedge \& Lenzen 1991, Burcelin et al. 2000). HFD feeding did not significantly affect pancreatic $P d x 1$ mRNA levels, but obviously increased Glut2 and insulin mRNA expression associated with elevated serum insulin concentrations. Therefore, hyperinsulinemia in obese individuals may correlate with improved $\beta$ cell insulin secretion. In contrast with HFDfed group, casein injection significantly reduced pancreatic $P d x 1$, Glut2, Gk, and insulin mRNA levels and serum insulin levels, indicating that chronic inflammation exacerbated HFD-induced islet $\beta$ cell dysfunction and accelerated the progression of obesity-related T2DM.

Recent evidences have suggested that increased apoptosis of pancreatic $\beta$ cells could explain insulin deficiency (Butler et al. 2003, Meier et al. 2005, Jurgens et al. 2011). However our data did not demonstrate that HFD feeding by itself for 14 weeks increased $\beta$ cell apoptosis. It is possible that casein injection could augment $\beta$ cell apoptosis in the presence of HFD with upregulated $B a x / B c l 2$ mRNA levels, suggesting that chronic inflammation could exacerbate $\beta$ cell apoptosis in HFD-fed individual.

Taken together, our results demonstrated that chronic inflammation exacerbated HFD-related $\beta$ cell dysfunction and apoptosis, resulting in glucose metabolism disorder. Obese patients with chronic inflammation are more prone to develop into T2DM much earlier.

\section{Declaration of interest}

The authors declare that there is no conflict of interest that could be perceived as prejudicing the impartiality of the research reported.

\section{Funding}

This work was financial supported by the National Natural Science Foundation of China (81070631, 81270493, 30971389, 81270789, 81200567, and Key Program nos 81030008 and 81390354), Major State Basic Research Development Program of China (973 Program nos 2012CB517700 and 2012CB517500).

\section{Author contribution statement}

Y W, T W, and J W carried out experiments and researched data, L Z performed the data analysis, Q $L$ researched data, $Z \mathrm{~V}$ reviewed manuscript and contributed discussion, J F M refined the manuscript, S H P reviewed manuscript, $Y \subset$ designed the project and experiments and wrote manuscript, and X Z R designed the project and reviewed manuscript.

\section{References}

Boden G \& Shulman GI 2002 Free fatty acids in obesity and type 2 diabetes: defining their role in the development of insulin resistance and $\beta$-cell dysfunction. European Journal of Clinical Investigation 32(Suppl 3) 14-23. (doi:10.1046/j.1365-2362.32.s3.3.x)

Burcelin R, Dolci W \& Thorens B 2000 Glucose sensing by the hepatoportal sensor is GLUT2-dependent: in vivo analysis in GLUT2-null mice. Diabetes 49 1643-1648. (doi:10.2337/diabetes.49.10.1643)

Butler AE, Janson J, Bonner-Weir S, Ritzel R, Rizza RA \& Butler PC 2003 $\beta$-Cell deficit and increased $\beta$-cell apoptosis in humans with type 2 diabetes. Diabetes 52 102-110. (doi:10.2337/diabetes.52.1.102)

Chen CM 2008 Overview of obesity in Mainland China. Obesity Research 9(Suppl 1) 14-21. (doi:10.1111/j.1467-789X.2007.00433.x)

Collins SC, Hoppa MB, Walker JN, Amisten S, Abdulkader F, Bengtsson M, Fearnside J, Ramracheya R, Toye AA, Zhang Q et al. 2010 Progression of 
diet-induced diabetes in C57BL6J mice involves functional dissociation of $\mathrm{Ca} 2(+)$ channels from secretory vesicles. Diabetes 59 1192-1201. (doi:10.2337/db09-0791)

Defronzo RA 2009 Banting Lecture. From the triumvirate to the ominous octet: a new paradigm for the treatment of type 2 diabetes mellitus. Diabetes 58 773-795. (doi:10.2337/db09-9028)

Eckel RH, Kahn SE, Ferrannini E, Goldfine AB, Nathan DM, Schwartz MW, Smith RJ \& Smith SR 2011 Obesity and type 2 diabetes: what can be unified and what needs to be individualized? Diabetes Care $\mathbf{3 4}$ 1424-1430. (doi:10.2337/dc11-0447)

El Assaad W, Buteau J, Peyot ML, Nolan C, Roduit R, Hardy S, Joly E, Dbaibo G, Rosenberg L \& Prentki M 2003 Saturated fatty acids synergize with elevated glucose to cause pancreatic $\beta$-cell death. Endocrinology 144 4154-4163. (doi:10.1210/en.2003-0410)

Ferrannini E \& Mari A $2004 \beta$ Cell function and its relation to insulin action in humans: a critical appraisal. Diabetologia 47 943-956. (doi:10.1007/ s00125-004-1381-z)

Godsland IF, Jeffs JA \& Johnston DG 2004 Loss of $\beta$ cell function as fasting glucose increases in the non-diabetic range. Diabetologia 47 1157-1166. (doi:10.1007/s00125-004-1454-z)

Guo S, Copps KD, Dong X, Park S, Cheng Z, Pocai A, Rossetti L, Sajan M, Farese RV \& White MF 2009 The Irs1 branch of the insulin signaling cascade plays a dominant role in hepatic nutrient homeostasis. Molecular and Cellular Biology 29 5070-5083. (doi:10.1128/МСВ. 00138-09)

Hotamisligil GS 2006 Inflammation and metabolic disorders. Nature $\mathbf{4 4 4}$ 860-867. (doi:10.1038/nature05485)

Hotamisligil GS, Arner P, Caro JF, Atkinson RL \& Spiegelman BM 1995 Increased adipose tissue expression of tumor necrosis factor- $\alpha$ in human obesity and insulin resistance. Journal of Clinical Investigation 95 2409-2415. (doi:10.1172/JCI117936)

Jurgens CA, Toukatly MN, Fligner CL, Udayasankar J, Subramanian SL, Zraika S, Aston-Mourney K, Carr DB, Westermark P, Westermark GT et al. $2011 \beta$-Cell loss and $\beta$-cell apoptosis in human type 2 diabetes are related to islet amyloid deposition. American Journal of Pathology 178 2632-2640. (doi:10.1016/j.ajpath.2011.02.036)

Lacraz G, Figeac F, Movassat J, Kassis N \& Portha B 2010 Diabetic GK/Par rat $\beta$-cells are spontaneously protected against $\mathrm{H}_{2} \mathrm{O}_{2}$-triggered apoptosis. A cAMP-dependent adaptive response. American Journal of Physiology. Endocrinology and Metabolism 298 E17-E27. (doi:10.1152/ajpendo. 90871.2008)

Li HQ, Wang BP, Deng XL, Zhang JY, Wang YB, Zheng J, Xia WF, Zeng TS \& Chen LL 2011 Insulin improves $\beta$-cell function in glucose-intolerant rat models induced by feeding a high-fat diet. Metabolism 60 1566-1574. (doi:10.1016/j.metabol.2011.01.018)

de Luca C \& Olefsky JM 2008 Inflammation and insulin resistance. FEBS Letters 582 97-105. (doi:10.1016/j.febslet.2007.11.057)

Ma KL, Ruan XZ, Powis SH, Chen Y, Moorhead JF \& Varghese Z 2008 Inflammatory stress exacerbates lipid accumulation in hepatic cells and fatty livers of apolipoprotein E knockout mice. Hepatology 48 770-781. (doi:10.1002/hep.22423)

Maedler K, Oberholzer J, Bucher P, Spinas GA \& Donath MY 2003 Monounsaturated fatty acids prevent the deleterious effects of palmitate and high glucose on human pancreatic $\beta$-cell turnover and function. Diabetes 52 726-733. (doi:10.2337/diabetes.52.3.726)

Meier JJ, Bhushan A, Butler AE, Rizza RA \& Butler PC 2005 Sustained $\beta$ cell apoptosis in patients with long-standing type 1 diabetes: indirect evidence for islet regeneration? Diabetologia 48 2221-2228. (doi:10.1007/s00125-005-1949-2)

Melloul D 2004 Transcription factors in islet development and physiology: role of PDX-1 in $\beta$-cell function. Annals of the New York Academy of Sciences 1014 28-37. (doi:10.1196/annals.1294.003)

Miura K, Takahashi Y \& Shirasawa H 1985 Immunohistochemical detection of serum amyloid A protein in the liver and the kidney after casein injection. Laboratory Investigation $\mathbf{5 3}$ 453-463.

Prentki M \& Nolan CJ 2006 Islet $\beta$ cell failure in type 2 diabetes. Journal of Clinical Investigation 116 1802-1812. (doi:10.1172/JCI29103)

Sachdeva MM \& Stoffers DA 2009 Minireview: Meeting the demand for insulin: molecular mechanisms of adaptive postnatal $\beta$-cell mass expansion. Molecular Endocrinology 23 747-758. (doi:10.1210/me. 2008-0400)

Schenk S, Saberi M \& Olefsky JM 2008 Insulin sensitivity: modulation by nutrients and inflammation. Journal of Clinical Investigation 118 2992-3002. (doi:10.1172/JCI34260)

Spranger J, Kroke A, Mohlig M, Hoffmann K, Bergmann MM, Ristow M, Boeing H \& Pfeiffer AF 2003 Inflammatory cytokines and the risk to develop type 2 diabetes: results of the prospective population-based European Prospective Investigation into Cancer and Nutrition (EPIC)Potsdam Study. Diabetes 52 812-817. (doi:10.2337/diabetes.52.3.812)

Tiedge M \& Lenzen S 1991 Regulation of glucokinase and GLUT-2 glucosetransporter gene expression in pancreatic B-cells. Biochemical Journal 279 899-901.

Wal JM 2002 Cow's milk proteins/allergens. Annals of Allergy, Asthma \& Immunology 89 3-10. (doi:10.1016/S1081-1206(10)62115-1)

Wang P, Mariman E, Renes J \& Keijer J 2008 The secretory function of adipocytes in the physiology of white adipose tissue. Journal of Cellular Physiology 216 3-13. (doi:10.1002/jcp.21386)

Winzell MS \& Ahren B 2004 The high-fat diet-fed mouse: a model for studying mechanisms and treatment of impaired glucose tolerance and type 2 diabetes. Diabetes 53(Suppl 3) S215-S219. (doi:10.2337/diabetes. 53.suppl_3.S215)

Xiang AH, Kawakubo M, Trigo E, Kjos SL \& Buchanan TA 2010a Declining $\beta$-cell compensation for insulin resistance in Hispanic women with recent gestational diabetes mellitus: association with changes in weight, adiponectin, and C-reactive protein. Diabetes Care 33 396-401. (doi:10.2337/dc09-1493)

Xiang FL, Lu X, Strutt B, Hill DJ \& Feng Q $2010 b$ NOX2 deficiency protects against streptozotocin-induced $\beta$-cell destruction and development of diabetes in mice. Diabetes 59 2603-2611. (doi:10.2337/db09-1562)

Zhang H, Ching S, Chen Q, Li Q, An Y \& Quan N 2008 Localized inflammation in peripheral tissue signals the CNS for sickness response in the absence of interleukin- 1 and cyclooxygenase- 2 in the blood and brain. Neuroscience 157 895-907. (doi:10.1016/ j.neuroscience.2008.09.038)

Zhang Y, Zhou B, Deng B, Zhang F, Wu J, Wang Y, Le Y \& Zhai Q 2012 Amyloid- $\beta$ induces hepatic insulin resistance in vivo via JAK2. Diabetes 62 1159-1166. (doi:10.2337/db12-0670)

Received in final form 28 August 2013

Accepted 10 September 2013

Accepted Preprint published online 12 September 2013 http://joe.endocrinology-journals.org DOI: 10.1530/JOE-13-0160
() 2013 Society for Endocrinology Printed in Great Britain 